\title{
Program Pelatihan Wasit Bola Basket Tingkat Pemula: Sebuah Studi Eksperimen
}

\author{
Beginner-Level Basketball Referee Training Program: An Experimental Study
}

\author{
Fahmi Respati Prakasa, Amung Ma'mun \& Dian Budiana \\ Universitas Pendidikan Indonesia, Bandung, Jawa Barat, Indonesia \\ respati44@yahoo.com,amung@upi.edu,dianbudiana@upi.edu
}

Naskah diterima tanggal 02/06/2019, direvisi akhir tanggal 24/06/2019, disetujui tanggal 31/07/2019

\begin{abstract}
Abstrak
Melihat kinerja tugas wasit basket merupakan suatu hal yang penting dalam sebuah pertandingan karena akan menyangkut hasil yang diperolah dalam pertandingan basket. Penelitian ini bertujuan untuk mengetahui dan menguji pengaruh dari pengembangan wasit melalaui program pembelajaran asynchronous learning, program pembelajaran campuran, dan program pembelajaran melalui metode konvensional dan melihat hubungan anatara nilai pengetahuan wasit dengan performa wasit saat memimpin pertandingan. Metode dalam penelitian ini adalah metode eksperimen dengan desain a three-threatment counterbalanced design, sebanyak 30 sampel yang digunakan dalam penelitian ini dipilih melalui teknik purposive sampling. Instrument dalam penelitian ini menggunakan format evaluasi wasit basket yang di keluarkan oleh Perbasi. Teknik pengolahan data menggunakan software mini tab 17 dengan menggunakan paired t test sample. Hasil penelitian ini menunjukan bahwa: 1) Terdapat pengaruh yang signifikan program pembelajaran asynchronous learning terhadap kinerja wasit bola basket. 2) Terdapat pengaruh yang signifikan program pembelajaran campuran terhadap kinerja wasit bola basket. 3) Terdapat pengaruh yang signifikan program pembelajaran konvensional terhadap kinerja wasit bola basket. 4) Terdapat hubungan yang signifikan antara ilmu pengetahuan wasit dengan performa wasit. Kesimpulan dari penelitian ini yaitu betapa pentingnya memilih program pembelajaran atau pelatihan guna meningkatkan pemahaman dan performa wasit basket. Kata Kunci: Performa Wasit Bola Basket, Program Pelatihan, Program Pembelajaran, Wasit Bola Basket.
\end{abstract}

\begin{abstract}
Seeing the performance of the basketball referee's duties is an important thing in a competition because it will involve the results obtained in a basketball match. This study aims to determine and examine the effects of refereeing development through asynchronous learning programs, mixed learning programs, and conventional methods oflearning programs and see the relationship between the value of referee's knowledge and the performance of the referee when leading matches. The method in this study is an experimental method with the design of a three-threat counterbalanced design, as many as 30 samples used in this study were selected through a purposive sampling technique. The instrument in this study used the basketball referee evaluation format issued by Perbasi. Data processing techniques using mini tab 17 software using a paired t-test sample. The results of this study indicate that: 1) There is a significant effect of asynchronous learning programs on the performance of basketball referees. 2) There is a significant effect of mixed learning programs on the performance of basketball referees. 3) There is a significant effect of conventional learning programs on the performance of basketball referees. 4) There is a significant relationship between referee science and the referee's performance. The conclusion of this study is how important it is to choose a learning or training program to improve the understanding and performance of basketball referees.
\end{abstract}

Keywords: Basketball Referee, Basketball Referee Performance, Learning Program, Training Program. 


\section{PENDAHULUAN}

Wasit adalah salah satu peran yang sangat penting dalam bidang olahraga, termasuk dari olahraga tim. Tidak jarang bagi wasit yang sedang memimpin pertandingan itu merasakan kecemasan ketika mereka mengatasi berbagai sumber stress (Adé, Ganière, \& Louvet, 2018). Karena performa wasit sangat menentukan suatu pertandingan agar tidak merugikan bagi salah satu tim yang sedang bertanding. Dalam perkembangan peraturan permainan bola basket yang dinamis apabila tidak dipahami akan menjadi boomerang bagi seorang wasit, apalagi dalam hal ini adalah seorang wasit yang masih pemula karena pengambilan keputusanpun harus berdasarkan prinsipprinsip yang ada dalam peraturan resmi bola basket. Semangat dan tujuan dari peraturan dan kebutuhan untuk menjungjung tinggi integritas dalam suatu pertandingan, konsisten dalam menerapkan akal sehat pada tiap pertandingan, konsisten dalam menjaga keseimbangan dan memutuskan apa yang benar untuk pertandingan (FIBA, 2010:29).

Keadaan seperti harus segera di evaluasi kemudian dilakukan perbaikan sehingga kesalahan-kesalahan yang telah di lakukan tidak terulang kembali atau dapat diminimalisir. Bagi para wasit belajar dari sebuah kejadian itu sangat penting karena dalam setiap pertandingan yang wasit akan pimpin banyak hal yang akan terjadi, pada program pengembangan wasit inilah mereka dirangsang untuk menganalisis dan mempelajari keputusan yang harus diambil dan dikaitkan dengan peraturan permainan. Hal yang dapat di lakukan adalah dengan memperbaiki dengan berbagai program pengembangan bagi para wasit pemula yaitu dengan program asynchronous learning atau pembelajaran tanpa tatap muka, program pelatihan atau pembelajaran dengan metode konvensional, dan metode pembelajaran campuran yaitu konvensional dan asynchronous learning.

Pelatihan merupakan suatu bentuk pembelajaran yang bermuara pada perubahan sehingga peran seseorang dalam mengembangakan keterampilan dapat mempunyai perubahan sikap dan perilaku. Kata media dalam media pembelajaran secara harifiah berarti perantara atau pengantar sedangkan kata pembelajaran diartikan sebagai suatu kondisi yang diciptakan untuk mebuat seseorang melakukan kegiatan belajar. Media pelatihan merupakan suatu komponen penting dalam sistem pelatihan, karena berfungsi sebagai penunjang proses dalam suatu pembelajaran yang bisa menjadikan orang yang sedang dalam pelatihan atau pembelajaran menjadi tergugah gairahnya dan termotivasi dengan media pelatihan yang beragam. Pelatihan atau pendidikan adalah proses belajar dan mengetahui yang berlanjut sepanjang hidup, bahkan kejadi biasa ataupun peristiwa yang kita alami disekitar kita dapat mendidik dan melatih kita, media pelatihan dan pembelajaran hadir dalam berbagai bentuk dan setiap bentuk mempengaruhi cara siswa belajar dan menafsirkan informasi (Preeti. J, 2014).

Dalam pembelajaran (instructional) sumber informasi adalah dosen, guru, instruktur, peserta didik, bahan bacaan dan laihalnya. Schramm (1997) mengemukakan bahwa media pembelajaran adalah adalah teknologi pembawa pesan yang dapat dimanfaatklan untuk keperluan pembelajaran. Selain itu media pembelajaran sebagai sarana fisik untuk menyampaikan isi atau materi pembelajaran maupun pelatihan (Briggs \& Ackerman, 1977). Tanpa media pembelajaran atau pelatihan maka komunikasi tidak akan terjalin dengan baik antara instruktur dengan siswa dalam proses pembelajaran dan pelatihan, karena pembelajaran dan pelatihan merupakan proses komunikasi dua arah karena media pembelajaran adalah segala sesuatu yang dapat digunakan untuk menyalurkan pesan dari pengirim yaitu instruktur dan penerima yaitu siswa, sehingga dapat merangsang pikiran, perasaan, perhatian dan minat siswa sehingga proses pembelajaran dan pelatihan bisa terjalin dengan baik dan dapat membuat perubahan, baik perubahan sikap, perilaku, maupun perubahan pola pikir.

Dengan demikian, media pembelajaran dianggap dapat memberikan penekanan pada 
posisi media sebagai wahana penyalur pesan atau informasi belajar untuk mengkondisikan seseorang untuk belajar. Dengan kata lain, pada saat kegiatan belajar mengajar berlangsung yang diterima siswa diperoleh melalui media. Hal ini sesuai dengna pendapat Briggs \& Ackerman (1977) yang menyatakan bahwa the physical means of conveying instructional content...book, films, video tapes, etc. dan disebutkan pula bahwa media sebagai alat untuk memberi perangsang bagi siswa supaya terjadi proses belajar (Briggs \& Ackerman, 1977). Menggaris bawahi bahwa media yang digunakan guru, instruktur atau siswa dengan baik dapat mempengaruhi efektifitas proses belajar dan mengajar. Media pembelajaran atau pelatihan yang baik adalah media yang dapat meningkatkan hasil dari belajar siswa, merangsang pembelajaran untuk mengingat apa yang telah dan sudah dipelajari selain memberikan rangsangan belajar baru, mengaktifkan sistem pembelajaran dalam memberikan tanggapan, umpan balik, dan juga bisa dapat mendorong mereka untuk melakukan praktik-praktik dengan baik dan benar.

Sehingga aplikasi media dan teknologi pendidikan, bisa merealisasikan suatu konsep teaching less learning more. Artinya secara fisik bisa saja kegiatan guru di kelas dikurangi, karena ada sebagian tugas guru yang didelegasikan pada media, namun tetap mendorong tercapainya hasil belajar siswa. Sumber belajar adalah segala sesuatu yang ada disekitar lingkungan kegiatan belajar yang dapat digunakan untuk membantu optimalisasi hasil belajar. Optimalisasi hasil belajar ini dapat dilihat tidak hanya dari hasil belajar (output) namun juga dilihat dari proses berupa interaksi siswa dengan berbagai macam sumber yang dapat merangsang untuk terjadinya proses belajar dan mempercepat penguasaan pengetahuan, keterampilan dan sikap positif terhadap bidang ilmu yang dipelajarinya. Pemanfaatan sumber belajar dapat dikatagorikan menjadi dua, yaitu sumber belajar yang sengaja dirancang untuk pembelajaran (by design) dan sumber belajar yang dapat langsung dimanfaatkan yang berada dilingkungan tempat kegiatan belajar yang tidak secara khsusus dirancang untuk pembelajaran (by utilization).

Pada dasarnya olahraga adalah tentang partisipasi baik itu dari para penyelenggara, atlit, maupun para wasit yang meimpin pertandingan. Dengan pengembangan olahraga telah memberikan kontribusi menjadi salah satu kekuatan untuk orang -orang yang berpartisipasi di dalamanya (Ha, Lee, \& Ok, 2016). Manusia merupaka mahluk yang dinamis dengan mobilitas yang tinggi, selain dalam mobilitas yang tinggi kinerja dalam berolahraga berkaitan dengan keterampilan motorik dan menjaga performa pada saat memimpin pertandingan. Karena tuntutan fisiologis dapat berdampak secara signifikan terhadap pengambilan keputusan wasit dan akan mempengaruhi kinerja wasit dalam suatu pertandingan (Vaquera, Mielgoayuso, Calleja-gonzález, \& Anthony, 2016). Kinerja berasal dari kata job performance atau actual performance yang berarti prestasi kerja atau prestasi sesungguhnya yang dicapai oleh seseorang sesuai dengan tanggung jawab yang diberikan kepadanya. Sedangkan pengertian lain menurut (Mathis \& Jackson, 2006:65), untuk pencapaian kinerja yang maksimal dalam olahraga diperlukan tahapan dan proses pembelajaran serta latihan yang harus dilakukan sesuai dengan apa yang dikemukakan Schmidt, Richard \& Lee, Timothy (2005) bahwa setiap manusia memiliki banyak bentuk keterampilan tinggal bagaimana kita bisa mengasah dan kita bisa memanfaatkannya menjadi sebuah kinerja yang maksimal.

Sama halnya dalam bidang perwasitan di bola basket bahwa setiap wasit memiliki kemampuan masing-masing dan berbeda satu sama lainnya, akan tetapi jika dalam hal pemahaman peraturan permainan setiap wasit harus memiliki kemampuan yang baik dan mennjang agar membuat kinerja dalam memimpin pertandingan menjadi tidak mengecewakan ataupun merugikan bagi salah satu atau kedua tim yang sedang bertanding. Kinerja tersebut merupakan hasil dari apa yang kita kerjakan, yang didalamnya terdapat cara kita menjalankan fungsi-fungsi 
dan manajemen kegiatan yang kita lakukan untuk mempertanggung jawabkan hasil dari apa yang kita kerjakan.

Kinerja seorang wasit merupakan hasil kerja atau prestasi sesungguhnya dari pertandingan yang dipimpinnya dari awal sampai akhir pertandingan. Bagaimana diperlukannya konsentrasi penuh dalam setiap memimpin pertandingan dan juga bagaimana caranya me-manage suatu pertandingan agar dapat dipercaya oleh kedua tim dan tidak merugikan salah satu ataupun kedua tim. Maka dari itu seorang wasit harus pandai dalam mempersiapkan dirinya sebelum memimpin pertandingan, karena kinerja wasit dalam pertandingan merupakan penentu hasil dari pertandingan itu sendiri dan seorang wasit harus dapat mempertanggung jawabkan setiap keputusan yang diambil ketika memimpin suatu pertandingan dengan tensi dan gengsi yang tinggi antara kedua tim dan kinerja dari wasit akan diuji di dalam sebuah pertandingan tersebut.

Ada beberapa penelitian sebelumnya yang relevan dengan apa yang sudah dijabarkan sebelumnya. Penelitian Schweizer, Plessner, Kahlert, \& Brand (2011) yang membahas tantangan untuk perancangan program pelatihan wasit dan memberikan tinjauan umum tentang beberapa metode yang digunakan dalam melatih perangkat pertandingan. Untuk membantu mereka mengembangkan tingkat keahlian yang lebih tinggi dalam periode yang singkat. potensi pemanfaatan alat berbasis video. Penelitian ini menunjukan bahwa program pelatihan pengambilan keputusan berbasis video secara substansial meningkatkan keputusan wasit sepakbola. Penelitian Clark (2002) menerangkan di dalamnya berisikan e-learning memberikan tingkat retensi yang jauh lebih tinggi. Tingkat penguatan lain dalame-learning yaitu belajar dapat diperkuat dengan hanya menggunakan teknologi untuk mendorong proses pembelajaran di masa akan datang. Penelitian Liao, Wang, Ran, \& Yang (2014) menarik kesimpulan bahwa e-learning telah menjadi trend penting dalam reformasi pendidikan, karena dengan bantuan teknologi dan informasi peserta didik dapat mengakses materi dari guru dan sumber lain dari waktu ke waktu dan ruang yang lebih efisien. Hasil dari penelitian ini siswa dapat menerima layanan pendukung belajar sesuai dengan kebutuhan belajar mereka, sumber daya virtual ini dapat dikirim dengan cara yang paling efektif. Penelitian Mendell (1987) yang melakukan pengembangan program kegiatan yang melibatkan keterampilan pengembangan, harus menilai apa kebutuhan diagnostic dan kemudian menentukan melalui perencanaan dan aktivitas apa yang mereka butuhkan.

\section{METODE PENELITIAN}

Penelitian ini menggunakan pendekatan kuantitatif. Pendekatan kuantitatif digunakan untuk mempresentasikan data yang diperoleh secara uji statistik. Metode yang digunakan dalam penelitian ini adalah metode eksperimen yang bertujuan untuk mengimplementasikanprogrampembelajaran yang akan digunakan. Dalam penelitian ini, metode penelitian yang digunakan adalah, Counter balanced Design, yaitu desain yang diimbangi mewakili teknik lain untuk menyamakan kelompok eksperimen dan pembanding (Fraenkel, Wallen, \& Hyun, 2012:275). Teknik pemilihan sampel dalam penelitian ini adalah purposive sampling karena peneliti dapat berasumsi mereka dapat menggunakan pengetahuan mereka tentang populasi untuk menilai apakah sampel tertentu akan representative atau tidak (Fraenkel, Wallen, \& Hyun, 2012:100).

Peneliti memilih anggota UKM basket di UPI yang berminat dalam pengembangan wasit karena intesitas kompetisi basket di Kota Bandung yang tinggi, dan selalu adanya latihan disetiap minggunya guna mendiskusikan hal-hal yang terjadi selama mempimpin pertandingan. Pelaksanaan program penelitian dilakukan kepada wasit tingkat pemula ini adalah pendidikan tahap awal dari sejumlah sesi dengan durasi maksimal $2 \mathrm{jam} / \mathrm{sesi}$. Kurikulum terdiri dari atas pokok-pokok penting yang harus dibahas mengacu kepada buku peraturan FIBA. Presentasi power point berisi pokokpokok penting dan tidak perlu membahas 
buku peraturan secara mendetail. Programprogram pengembangan wasit diberikan sebanyak 12 kali pertemuan 10 kali diberikan untuk treatment sedangkan untuk 2 pertemuan untuk pre-test dan post-test.

Sedangkan untuk proses pengambilan data dan mengetahui informasi dari para sampel penelitian dalam arti untuk mengetahui laporanlaporan pribadinya atau hal-hal lain pada saat tugas menjadi seorang wasit. Penilaian dari performa wasit ini dinilai melaui form penilaian kordinator wasit yang di buat oleh PERBASI untuk memudahkan penilaian dari performa wasit pada saat memimpin pertandingan dilapangan. Sedangkan untuk mengetahui kognitif dari seorang wasit menggunakan tes soal yang digunakan pada saat penataran perwasitan tingkat dasar atau lisensi C. Dalam form penilaian ini lebih kepada keseluruhan performa pada saat wasit dilapangan untuk memimpin pertandingan, adapaun contoh lembar penilaian yang digunakan coordinator wasit pada saat kejuaraan. Teknik analisa dan pengolahan data yang diperoleh kemudian diuji normalitas dengan menggunakan software minitab 17, kemudian dilanjutkan dengan uji homogenitas, uji t beda rata-rata dan regression analysis untuk melihat korelasi antara performa dan ilmu pengetahuan wasit.

\section{HASIL DAN PEMBAHASAN 3.1 Hasil}

Data yang diperoleh dari hasil penelitian merupaka data pre-test dan post-test. Pengambilan data yang dilakukan sebelum sampel diberikan pelrakuan merupakan data pretest sedangkan untuk data post-test di dapatkan ketika sampel sudah mendapatkan perlakuan. Kedua tes tersebut dilakukan kepada ketiga kelompok sampel. Data yang sudah didapat tersebut kemudian perlu diolah dan dianalisis guna menjawab rumusan masalah dan menguji hipotesis dalam penelitian ini. Oleh karena itu pada penelitian ini, terlebih dahulu peneliti memaparkan secara sederhana keseluruhan dari hasil penelitian. Berikut ini peneliti menampilkan data skor yang sudah didapatkan dalam penelitian dalam gambar di bawah ini

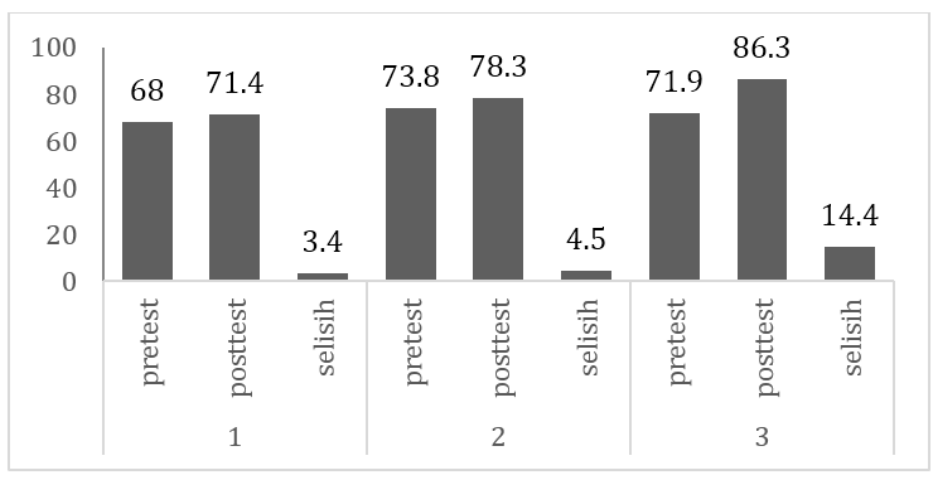

Gambar 1. Nilai Pre-Test, Post-Test dan selisihnya

Berdasarkan gambar 1 dapat diketahui bahwa jumlah sampel tiap kelompok adalah 10 orang. Kelompok 1 dengan rata-rata nilai pre-test yaitu 68 , rata-rata nilai post-test 71,4 dan selisih antara pre-test dan post-test 3,4. Sedangkan untuk kelompok treatment 2 dengan rata-rata nilai pre-test 73,8 , sedangkan nilai dari post-test adalah 78,3 , sedangnkan antara nilai pre-test dan pos test adalah 4,5. Dan treatment kelompok 3 dengan rata-rata nilai pre-test adalah 71,9 dan rata-rata nilai post-test adalah 86,3 dan selisi antara pre-test dan post-test adalah 14,4.

Gambar 1 memperlihatkan bahwa rerata nilai pre-test tertinggi ada pada kelas treatment 2, diikuti dengan kelas treatment 3 dan kelas treatment 1 setelah di lakukan treatment diujikan kembali dan menghasilkan nilai post-test pada setiap kelas treatment. Kelas treatment 3 menghasilkan nilai rerata post-test yang lebih tinggi dari pada yang lain. Artinya treatment dengan adanya tatap muka memberikan hasil yang lebih baik dibanding treatment lainnya. Selain itu kelas treatment 2 memberikan hasil yang lebih unggul dibanding kelas treatment 1 , artinya treatment dengan metode campuran lebih unggul dibandingkan kelas treatment 1 , artinya treatment campuran lebih baik dari pada tanpa adanya tatap muka 
atau asyncronous learning. Hal ini diperkuat dengan melihat selisih rerata nilai pre-test dan

post-test pada setiap treatment yang dilakukan.

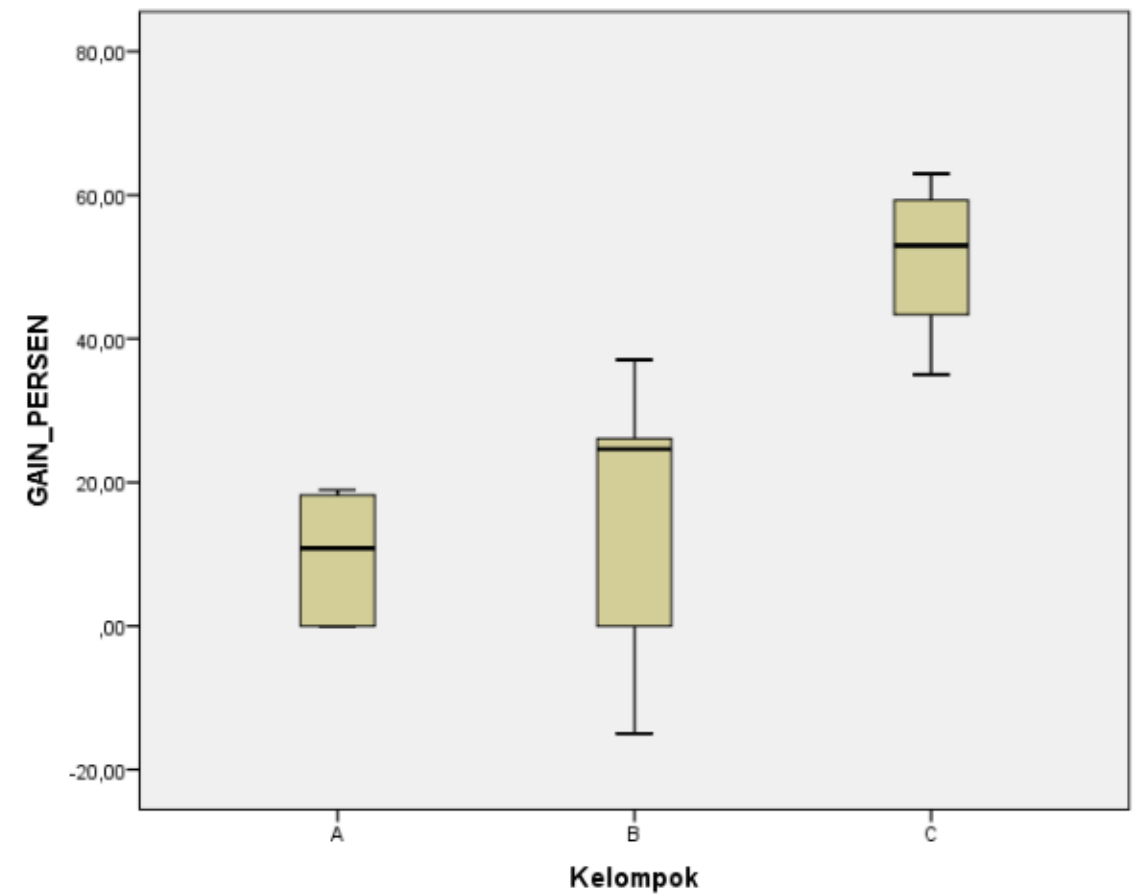

Gambar 2. Diagram N-Gain Skor

Berdasarkan gambar 2 terlihat bahwa ketiga kelompok memiliki nilai $n$-gain yang berbeda-beda. Pada kelompok 1 nilai median persentase n-gain sekitar $10.8108 \%$ dengan persentase minimum $0 \%$ dan maksimum 18.92\%. Pada kelompok 2 terlihat bahwa persentase n-gain cukup beragam terlihat dari gambar yang cukup panjang. Persentase mininum dan maksimum pada kelompok 2 masing-masing sebesar $15.00 \%$ dan $37.00 \%$ sedangkan mediannya sebesar 24.6296\%. Kelompok 3 memiliki rentang nilai persentase n-gain yang lebih tinggi dibanding 2 kelompok lainnya. Nilai minimum dan maksimum pada kelompok 3 masing-masing sebesar 35\% dan $62.96 \%$ dengan mediannya sebesar $52.9530 \%$.

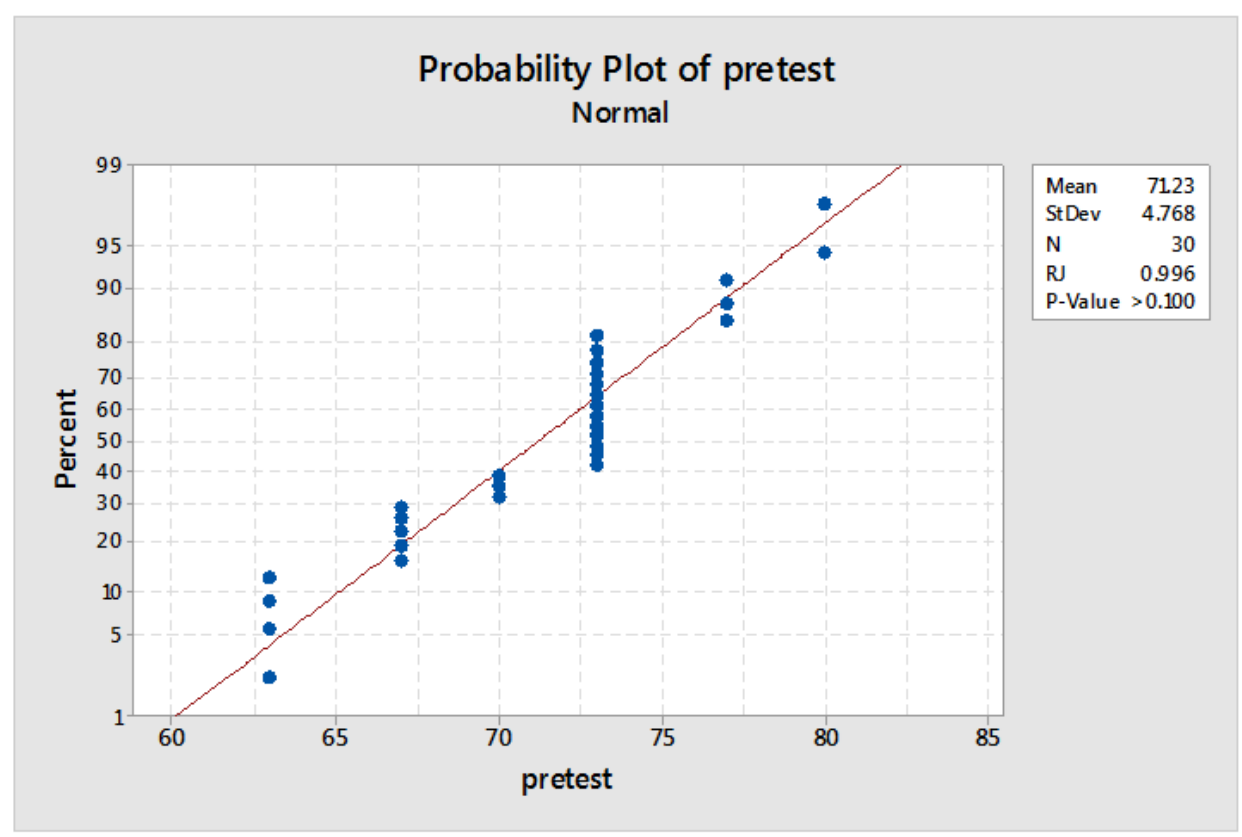

Gambar 3. Grafik uji normalitas 
Berdasarkan gambar 3, uji normalitas terlihat bahwa data sudah berada di sekitar garis linear artinya data skor pre-test pengetahuan wasit dari kelas eksperimen dan kelas kontrol berasal dari populasi yang berdistribusi normal. Selanjutnya uji homogenitas antar treatment adalah bersifat homogen dengan hasil test of homegenity berikut ini:

Tabel 1. Test of homogeneity treatment $1 \&$ treatment 2

\begin{tabular}{ccccc}
\hline Method & DF1 & DF2 & Statistic & P-Value \\
\hline Bonett & 1 & - & 1.87 & 0.172 \\
\hline Levene & 1 & 18 & 2.27 & 0.150 \\
\hline
\end{tabular}

Tabel 2. Test of homogenity treatment $1 \&$ treatment 3

\begin{tabular}{ccccc}
\hline Method & DF1 & DF2 & Statistic & P-Value \\
\hline Bonett & 1 & - & 0.00 & 0.982 \\
\hline Levene & 1 & 18 & 0.00 & 0.949 \\
\hline
\end{tabular}

Tabel 3. Test of homogenity treatment $2 \&$ treatment 3

\begin{tabular}{ccccc}
\hline Method & DF1 & DF2 & Statistic & P-Value \\
\hline Bonett & 1 & - & 1.76 & 0.185 \\
\hline Levene & 1 & 18 & 1.98 & 0.177 \\
\hline
\end{tabular}

Selanjutnya uji $-\mathrm{T}$ beda rata-rata dengan hasil tiap treatment di hasilkan dengan tabel berikut ini:

Table 4. Paired t-test treatment 1

\begin{tabular}{lcccc}
\hline & N & Mean & St Dev & Mean \\
\hline Pre 1 & 10 & 68.00 & 4.83 & 1.53 \\
\hline Post 1 & 10 & 71.40 & 3.84 & 1.21 \\
\hline Difference & 10 & -3400 & 2.633 & 0.833 \\
\hline 95\% CI for mean difference: $(-5.284 ;-1.516)$ \\
T-Test of mean difference $=0($ vs $\neq 0):$ \\
T-Value $=-4.08$ \\
P-Value $=0$.
\end{tabular}

Kesimpulan dari hasil tabel 1 hingga 4 yaitu terdapat perbedaan yang signifikan antara nilai pre-test dan post-test pada treatment 1. Berdasarkan dari Tabel Paired T-Test juga terlihat bahwa nilai rerata skor pengetahuan wasit pada sampel mengalami peningkatan nilai post-test yaitu dengan nilai pre-test 68.00 menjadi 71.40. Hal ini berarti perbedaan yang signifikan ini mengindikasikan bahwa treatment 1 memberi pengaruh yang positif.

Tabel 5. Paired t-test treatment 2

\begin{tabular}{lcccc}
\hline & N & Mean & St Dev & Mean \\
\hline Pre 2 & 10 & 73.80 & 2.74 & 0.87 \\
\hline Pos 2 & 10 & 78.30 & 4.40 & 1.39 \\
\hline Difference & 10 & -4.50 & 4.88 & 1.54 \\
\hline 95\% CI for mean difference: $(-7.99 ;-1.01)$ \\
T-Test of mean difference $=0(\mathrm{vs} \neq 0):$ \\
T-Value $=-2.91$ P-Value $=0.017$
\end{tabular}

Kesimpulan dari hasil tabel 5 yaitu terdapat perbedaan yang signifikan antara nilai pre-test dan post-test pada treatment 2. Berdasarkan dari Tabel Paired T-Test juga terlihat bahwa nilai rerata skor pengetahuan wasit pada mahasiswa mengalami peningkatan nilai post-test yaitu dengan nilai pre-test 73.80 menjadi 78.30 . Hal ini berarti berbedaan yang signifikan ini mengindikasikan bahwa treatment 2 memberi pengaruh yang positif.

Tabel 6. Paired t-test treatment 3

\begin{tabular}{lcccc}
\hline & N & Mean & St Dev & Mean \\
\hline Pre 3 & 10 & 71.90 & 4.79 & 1.52 \\
\hline Pos 3 & 10 & 86.60 & 2.50 & 0.79 \\
\hline Difference & 10 & -14.40 & 4.40 & 1.39 \\
\hline 95\% CI for mean difference: $(-17.55 ;-11.25)$ \\
T-Test of mean difference $=0(\mathrm{vs} \neq 0):$ \\
T-Value $=-10.34$ P-Value $=0.000$
\end{tabular}

Kesimpulan dari hasil tabel 6 yaitu terdapat perbedaan yang signifikan antara nilai pre-test dan post-test pada treatment 3. Berdasarkan dari Tabel Paired T-Test juga terlihat bahwa nilai rerata skor pengetahuan wasit pada mahasiswa mengalami peningkatan nilai post-test yaitu dengan nilai pre-test 71.90 menjadi 86.30. Hal ini berarti berbedaan yang signifikan ini mengindikasikan bahwa treatment 3 memberi pengaruh yang positif. Sedangkan hasil dari korelasi antara nilai pengetahuan wait dan performa wasit dengan hasil berikut :

Tabel 7. Model summary regression analysis

\begin{tabular}{cccc}
\hline S & R-sq & R-sq(adj) & R-sq(pred) \\
\hline 5.24182 & $74.33 \%$ & $73.41 \%$ & $70.06 \%$
\end{tabular}

Pearson correlation of post and performa $=0.862$

P-Value $=0.000$ 
Dengan kesimpulan dari hasil tabel 7 yaitu terdapat hubungan antara ilmu pengetahuan wasit dengan performa wasit. Nilai hubungannya adalah sebesar 0.933. Nilai tersebut mengindikasi bahwa ilmu pengetahuan wasit memiliki hubungan yang kuat terhadap performa wasit. Selain itu diperoleh nilai R-square sebesar $74.33 \%$ artinya bahwa performa wasit dipengaruhi oleh ilmu pengetahuan wasit sebesar $74.33 \%$, sedangkan sisanya yaitu $100 \%-74.33 \%=$ $25.67 \%$, dipengaruhi oleh faktor-faktor lain yang tidak diteliti oleh penulis.

Selanjutnya adalah analisis regresi sederhana. Teknik analisis regresi sederhana digunakan untuk mengetahui bagaimana variabel dependen (Y) performa wasit dapat diprediksikan melalui variabel independen (X) ilmu pengetahuan. Regresi linear sederhana memiliki persamaan sebagai berikut:

$$
\mathrm{Y}=\mathrm{a}+\mathrm{bX}
$$

Dari pengolahan data dengan menggunakan fasilitas yang ada dalam software minitab 17 didapat nilai regresi pada pengaruh ilmu pengetahuan terhadap performa wasit berupa nilai:

Tabel 8. Coefficients

\begin{tabular}{lccccc}
\hline \multicolumn{1}{c}{ Term } & Coef & SE Coef & T-Value & P-Value & VIF \\
\hline Constant & -22.3 & 10.8 & -2.07 & 0.048 & \\
\hline Pengetahuan & 1.229 & 0.137 & 9.00 & 0.000 & 1.00 \\
\hline $\mathrm{a}=-22.3$ & & & & & \\
$\mathrm{~b}=1.229$ & & & & & \\
\end{tabular}

Pada tabel 8, nilai koefisien regresi yang diperoleh sudah signifikan ditandai dengan nilai signifikansi yang sudah kurang dari 0.05 , sehingga didapat persamaan regresi sebagai berikut:

\section{Performa Wasit $(\mathrm{Y})=-22.3+1.229$ Ilmu pengetahuan $(\mathrm{X})$}

Menurut persamaan diatas dapat diketahui bahwa. Koefisien regresi nilai ilmu pengetahuan wasit adalah 1.229 , yang artinya setiap terjadi kenaikan pada nilai ilmu pengetahuan wasit sebesar satu satuan maka akan terjadi peningkatan dalam performa wasit sebesar 1.229.

\subsection{Pembahasan}

Pembahasan dari hasil treatment 1 yaitu terdapat pengaruh yang signifikan dalam Penerapan program pengembangan wasit bola basket melalui program asynchcronous learning terhadap kinerja wasit bola basket. Menurut Kanuka \& Rourke (2008) teknologi dari Asyncronous learning atau pertemuan tanpa tatap muka ini dapat meningkatkan kualitas dan meringankan efektivitas biaya. Dalam penelitian ini terdapat perbedaan yang signifikan anatara nilai pre-test dan post-test pada treatment 1. Berdasarkan dari tabel Paired t-test juga terlihat bahwa nilai rerata skor pengetahuan wasit pada sampel mengalami peningkatan nilai post- test yaitu dengan nilai pre-test 68.00 menjadi 71.40. hal ini berarti memiliki perbedaan yang signifikan ini mengindikasikan bahwa treatment 1 memberikan pengaruh yang positif.

Selanjutnya hasil dari treatment 2 yaitu terdapat pengaruh yang signifikan dalam penerapan program pengembangan wasit bola basket melalui program asynchronous learning dan pembelajaran konvensional atau tatap muka memiliki pengaruh yang signifikan terhadapa kinerja wasit bola basket. Berdasarkan hasil penelitian bahwa terdapat perbedaan yang signifikan anatara nilai pre-test dan post-test pada treatment 2. Berdasarkan dari tabel $t$-test juga terlihat bahwa nilai rerata skor engetahuan wasit pada mahasiswa mengalami penongkatan nilai post-test yaitu dengan nilai pretest 73.80 menjadi 78.80 . hal ini berarti memiliki perbedaan yang signifikan yang mengindikasikan bahwa treatment 2 memberi pengaruh yang postif. Begitupun dari 
penelitian sebelumnya strategi yang efektif untuk mengurangi kerugian dari treatment 1 dari hal ini adalah dengan menawarkan program e-learning campuran (campuran kursus online dan kelas konvensional. Ini adalah pilihan yang baik dan banyak perguruan tinggi atau pelatihan sedang bergerak dalam implementasi campuran ini, namun tidak dapat dipungkiri penawaran seperti ini akan terus menghadirkan hambatan akses bagi para siswa (Kanuka \& Rourke, 2008).

Untuk treatment 3 hasilnya terdapat pengaruh yang signifikan dalam penerapan pengembangan program wasit melalui pembelajaran konvensional atau tatap muka. Dalam hal ini terdapat perbedaan yang signifikan antara nilai pre-test dan post-test pada treatment 3. Berdasarkan dari Tabel Paired T-Test juga terlihat bahwa nilai rerata skor pengetahuan wasit pada mahasiswa mengalami peningkatan nilai post-test yaitu dengan nilai pre-test 71.90 menjadi 86.30. Hal ini berarti berbedaan yang signifikan ini mengindikasikan bahwa treatment 3 memberi pengaruh yang positif. Karena dalam pengaturan pembelajaran konvensional akan memberikan manfaat karena guru dan siswa bertemu dikelas sehingga mereka dapat mengembangkan kontak mata sebagai komunikasi non verbal dan guru dapat berhenti atau menjelaskan lebih detail ketika siswa terlihat bingung (Mcdowall et al., 2016).

Sedangkan selanjutnya yaitu hubungan antara ilmu dan pengetahuan wasit ternyata terdapat hubungan yang signifikan antara ilmu pengetahuan wasit dengan performa wasit. Hubungan antara ilmu pengetahuan wasit dengan performa wasit. Nilai hubungannya adalah sebesar 0.933. Nilai tersebut mengindikasi bahwa ilmu pengetahuan wasit memiliki hubungan yang kuat terhadap performa wasit. Selain itu diperoleh nilai R-square sebesar 74.33\% artinya bahwa performa wasit dipengaruhi oleh ilmu pengetahuan wasit sebesar $74.33 \%$, sedangkan sisanya yaitu $100 \%-74.33 \%=$ $25.67 \%$, dipengaruhi oleh faktor-faktor lain yang tidak diteliti oleh penulis. Selain itu nilai koefisien regresi yang diperoleh sudah signifikan ditandai dengan nilai signifikansi yang sudah kurang dari 0.05 , sehingga didapat persamaan regresi, yang diketahui bahwa koefisien regresi nilai ilmu pengetahuan wasit adalah 1.229 , yang artinya setiap terjadi kenaikan pada nilai ilmu pengetahuan wasit sebesar satu satuan maka akan terjadi peningkatan dalam performa wasit sebesar 1.229 .

\section{KESIMPULAN}

Dari hasil temuan bahwa memang e-learning memiliki pengaruh yang signifikan dari hasil program pengembangan melalui e-learning namun sedikit kurang efektif dari pada metode campuran yang berada di bawah metode konvensional yang berarti memang pembelajaran dengan tatap muka secara langsung lebih baik di bandingkan dengan metode e-learning atau tanpa tatap muka maupun dengan metode campuran antara kelas konvensional dengan kelas e-learning. Pada pembelajaran e-learning campuran peserta didik lebih banyak menggunakan intruksi berbasis komputer ataupun gadget daripada mereka yang melakukan dengan cara pengajaran konvensional maupun ansyncronous learning. (Clark, 2002) mengungkapkan bahwa memang bahwa pembelajaran melalui tanpa tatap muka ataupun e-learning dapat meningkatkan partisipasi melalui interaktivitas namun konten yang di cerna tidak maksimal namun hanya sebatas pada apa yang di berikan oleh pengajar atau pelatih melalui media elektronik. Pada program e-learning harus memerlukan perencanaan, pemantauan, dan kontrol yang kuat untuk membuat e-learning tersebut menjadi lebih efektif, namun masih banyak program e-learning ini tidak mewakili solusi yang efisien, inilah sebabnya mengapa banyak program e-learning di dunia telah gagal dan beberapa tidka memberikan program yang berkualitas (Safavi, 2008).

Teknologi e-learning memiliki potensi untuk memfasilitasi pembelajaran yang lebih tinggi dengan teknologi komunikasi sinkron berbasis teks. Tetapi peluang untuk mengembangkan keterampilan orasi yang 
bersifat sementara hilang. Seperti pada poin sebelumnya, salah satu cara untuk mengatasi hilangnya keterampilan adalah dengan menggunakan alat konferensi audio atau video. Sementara dicatat oleh salah satu peserta bahwa alat ini terus menjadi rumit dan mahal, program akses terbuka (seperti Skype) menjadi tersedia secara luas, dan dengan cara yang tidak menderita dari banyak masalah teknis dan biaya dari video yang lebih lama dan alat konferensi. Teknologi dari e-learning atau pertemuan tanpa tatap muka ini dapat meningkatkan kualitas dan meringankan efektivitas biaya, tapi itu juga dapat mengakibatkan hilangnya beberapa momen yang biasa di kelas pengajaran atau pelatihan berbasis konvensional.

Strategi yang efektif untuk mengurangi kerugian dari hal ini adalah dengan menawarkan program e-learning campuran (campuran kursus online dan kelas konvensional. Ini adalah pilihan yang bagi dan banyak perguruan tinggi atau pelatihan sedang bergerak dalam implementasi campuran ini, namun tidak dapat dipungkiri penawaran seperti ini akan terus menghadirkan hambatan akses bagi para siswa (Kanuka \& Rourke, 2008). Secara umum, e-learning mengakui awal era baru dalam penyediaan pendidikan. Tapi alangkah lebih baiknya e-learning dapat digunakan dalam mode "blended learning" di mana program pembelajaran tatap muka dan tanpa tatap muka berjalan secara paralrel
(Safavi, 2008).

Namun dalam penelitian ini yang lebih unggul yaitu kelas konvensional atau kelas dengan cara bertatap muka secara langsung karena kehadiran regular di kelas membantu para siswa yang sedang pelatihan berinteraksi dengan individu lain seusia mereka, menjadi lebih disiplin, mengikuti jadwal regular dan meningkatkan kewaspadaan mental mereka. Pelatihan dikelas membantu para siswa dan instruktur untuk saling mengenal dengan lebih baik. Hal ini memungkinkan instruktur untuk mengenal siswa dan mengevaluasi kekuatan dan kelemahan mereka dengan lebih baik, bisa bertindak sebagi mentor, dan membimbing siswa pelatihan dalam kemungkinan karir mereka. Di kelas konvesional ini siswa dapat langsung berbagi pandangan dan mejelaskan pertanyaan mereka sendiri kepada instruktur sehingga pertanyaan mereka bisa segera di jawab, selain itu pertanyaan itupun bisa di lempar ke siswa lainnya agar merangsang kinerja otak agar lebih baik lagi. Karena sebagian besar waktu dan catatan kelas mereka sangat berguna untuk belajar kembali dan memungkin untuk lulus ujian lebih besar. Bisa memahami pola tanya jawab dan dengan cepat saran yang diberikan oleh instruktur bisa di terima, siswa juga dapat merasa lebih merasa bermanfaat untuk belajar secara konvensional daripada ketika menggunakan catatan online umum dan ataupun saran yang tersedia di internet.

\section{DAFTAR PUSTAKA}

Adé, D., Ganière, C., \& Louvet, B. (2018). The role of the referee in physical education lessons : student experience and motivation. Physical Education and Sport Pedagogy, O(0), 1-13. https://doi.org/10.1080/1740898 9.2018.1455818.

Briggs, L. J., \& Ackerman, A. S. (1977). Instructional design : Principles and Applications. New Jersey: Educational Technology Publications.

Cantoni, V., Cellario, M., \& Porta, M. (2004). Perspectives and challenges in e-learning : towards natural interaction paradigms. https://doi.org/10.1016/j.jvlc.2003.10.002.

Clark, D. (2002). Psychological myths in e-learning. Medical Teacher, 24(6), 598-604. https://doi.org/10.1080/0 142159021000063916.

FIBA. (2010). PERATURAN RESMI BOLA BASKET 2010. Retrieved from https://mainbasket.files.wordpress. com/2011/07/peraturan-resmi-bola-basket-2010.pdf.

Fraenkel, J. R., Wallen, N. E., \& Hyun, E. (2012). How to Design and Evaluate Research in Education (8th Edition). Retrieved from https://www.amazon.com/Design-Evaluate-Research-Education-Book/dp/ B008A0NXF6.

Ha, J., Lee, K., \& Ok, G. (2016). The International Journal of the History of Sport From Development of Sport to Development through Sport : A Paradigm Shift for Sport Development in South Korea. 3367(February). 
https://doi.org/10.1080/09523367.2015.1062756..

Liao, J., Wang, M., Ran, W., \& Yang, S. J. H. (2014). Collaborative cloud: a new model for e-learning. Innovations in Education and Teaching International, 51(3), 338-351. https://doi.org/10.1080/14703297.2013.791 554.

Mathis, R. L., \& Jackson, J. H. (2006). Human Resource Management = Manajemen Sumber Daya Manusia. Retrieved from https://openlibrary.telkomuniversity.ac.id/pustaka/7838/human-resource-managementmanajemen-sumber-daya-manusia-10-e-.html.

Mcdowall, S., Lin, L., Mcdowall, B. S., Ph, D., Lin, L., \& Ph, D. (2016). A Comparison of Students 'Attitudes toward Two Teaching Methods : Traditional versus Distance Learning A Comparison of Students ' Attitudes toward Two Teaching Methods : Traditional versus Distance Learning. 3758(June). https:// doi.org/10.1080/10963758.2007.10696879..

Mendell, R. (1987). Developing an Activity Program that Perpetuates Developmental Skills. Activities, Adaptation \& Aging, 9(4), 79-84. https://doi.org/10.1300/J016v09n04_06

Preeti. J. (2014). Education and Role of Media in Education System. 2(3), 174-177.

Safavi, a a. (2008). Developing Countries and E-Learning Program Development. Journal of Global Information Technology Management, 11(December), 47-65. https://doi.org/10.1080/1097198X.2008.10856473.

Schmidt, Richard, A., \& Lee, Timothy, D. (2005). Motor control and learning: A behavioral emphasis. Retrieved from https://psycnet.apa.org/record/2005-04225-000.

Schramm, W. (1997). Big Media, Little Media : Tools and Technologies for Instruction|. Retrieved from https:// www.researchgate.net/publication/31764634_Big_Media_Little_Media_Tools_and_Technologies_ for_Instruction_W_Schramm.

Schweizer, G., Plessner, H., Kahlert, D., \& Brand, R. (2011). A Video-Based Training Method for Improving Soccer Referees' Intuitive Decision-Making Skills. Journal of Applied Sport Psychology, 23(4), 429442. https://doi.org/10.1080/10413200.2011.555346.

Vaquera, A., Mielgo-ayuso, J., Calleja-gonzález, J., \& Anthony, S. (2016). Sex differences in cardiovascular demands of refereeing during international basketball competition. 3847(April). https://doi.org/10.108 0/00913847.2016.1158622. 